\title{
The Monkey as a Psychological Subject
}

\author{
Harry F. Harlow
}

Published online: 20 August 2008

(C) The Author(s) 2008. This article is published with open access at Springerlink.com

\begin{abstract}
Many species in long-term captivity have tried to kill time by playing friendly games with their warders. In the end, only rhesus monkeys (Macaca mulatta) could tolerate the tedious hide-and-seek games that their human jailers prefer to play. In this article, written many years before the Stockholm syndrome was first described, the author relates how it was eventually discovered which species is most willing to contribute to the development of a genuinely scientific human psychology.
\end{abstract}

Keywords Interspecies cooperation - Stockholm syndrome ·

Comparative psychology $\cdot$ Rhesus monkeys $\cdot$ Harlow $\cdot$ History of psychology

\section{Introduction to Monkey Research}

My interest in psychological research on monkeys stemmed primarily from a single statement made by the chairman of my department shortly after I began my academic career. At our first meeting I asked him, "Where is the animal laboratory?" to this he replied, "They tore it down last summer."

Fortunately Madison still possessed an animal laboratory, although of a very different kind, the Vilas Park Zoo, which included a fine and diverse collection of monkeys and apes, housed in a modern building. Furthermore, the director of the zoo, Mr. Winkleman, was extremely cooperative. He gave us free rein to test any and all the animals, and assigned us the four foot wide area between the cages and the guard rail for our test equipment. The test that we chose was the delayed reaction, a measure of the animal's ability to remember which one of two cups had been baited with food. The equipment (see Figs. 1 and 2) was simple, a bare table and two tin

Harry F. Harlow died in 1981 and Dr. Frank C.P. van der Horst (fhorst@fsw.leidenuniv.nl) of Leiden University stands as the person to addess correspondence to.

H. F. Harlow

University of Wisconsin-Madison, Harlow Primate Laboratory,

22 N Charter St, Madison, WI 53715, USA 
cups. While the animals watched, food was placed under one of the cups and after a predetermined period of delay the monkey or ape was permitted to make a choice. The previous research on the delayed reaction had indicated that this test should be an excellent measure of general intellectual ability, and if this were true we believed that maximum length of delay would correlate highly with the zoologists' conception of each of the monkey's and ape's position in the phyletic scale.

The zoo's collection of primates, the order of animals to which man belongs, ranged from the lowest to the highest, from a lemur, an animal that looks more like a fox than a monkey, to two chimpanzees and an orangutan, both of which are anthropoid apes, the family of primates representing man's closest living kin.

The lemur fortunately was not one of the nocturnal species, and he cooperated to the full extent of his limited capacities. He frequently behaved, however, in a most unmonkeylike manner, and as often as not knocked over the cups with his nose instead of his hands and picked up the food with his mouth instead of first grasping it with his fingers. In spite of the fact that he failed to solve any but the shortest delays, he was a well-mannered animal who accepted his position as imbecile of the primate order with perfect grace.

The Vilas Park Zoo possessed two representatives of the New World monkeys, a pair of cebus monkeys. These monkeys are best known as the only kind of animal that with the aid of a hand organ and a tin cup can support a human being. Cebus monkeys as we shall see have many virtues but their performances on delayed reactions were far from spectacular. The animals were caged together and we could not separate them. We speculated at the time that their limitations might stem largely from emotional traits since they usually exhibited all the stability of a group of 5 -year-olds during the closing hour of a birthday party, and subsequent research confirmed, at least in part, our assumptions.

The Madison lab has always maintained a well-balanced collection of Old World monkeys. When we began our work baboons were available, an enormous sphinx baboon and a Hamadryas baboon, a living likeness of the appropriate Egyptian hieroglyphic. The facility with which these monkeys solved delayed reaction problems made it obvious that behind the doglike muzzles was a very advanced

Fig. 1 Original delayed response apparatus used at Vilas Park Zoo

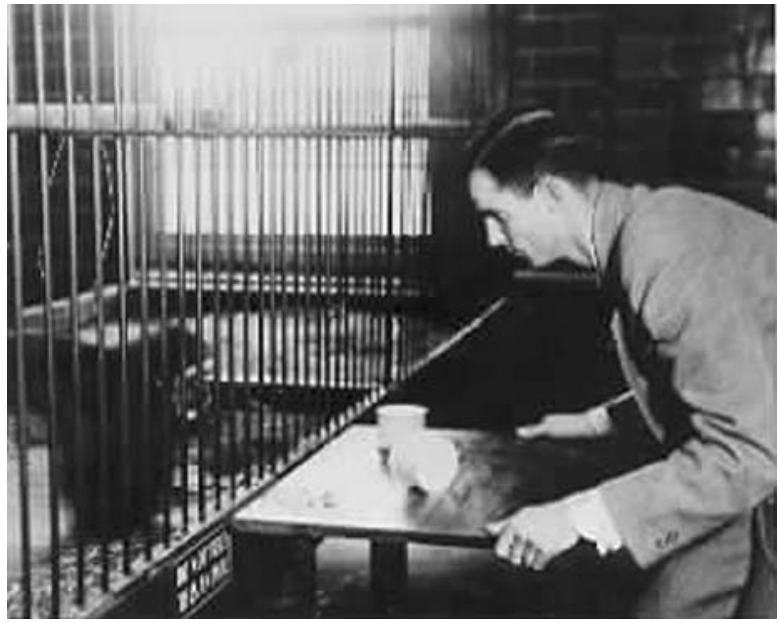


Fig. 2 Apparatus for comparing delayed response with stimuli in horizontal and vertical position

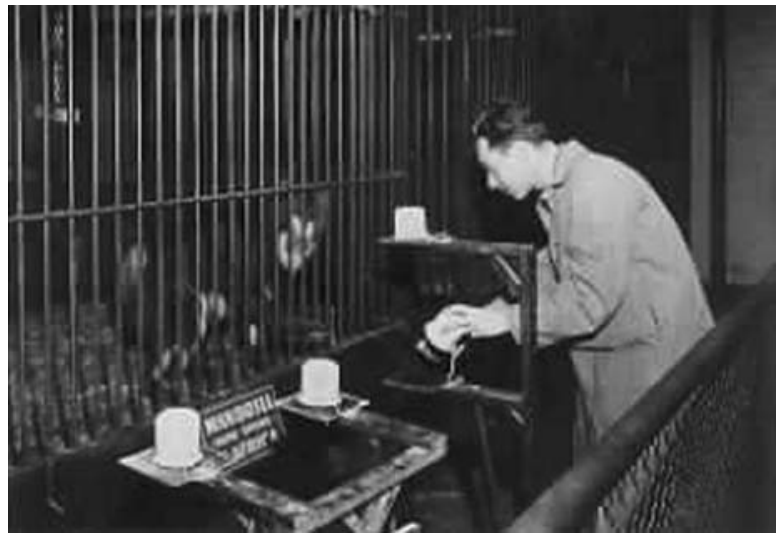

brain, and the skill with which they displaced the cups demonstrated that walking on one's hands does not destroy skilled coordination between fingers and thumb. Perhaps there is something to be said for sitting on one's hands.

The baboons might be the finest test animals of all the monkeys were it not for their size and intransigent dispositions. Tommy, the sphinx baboon was intellectually endowed, but testing was difficult because after a few errors he would scream, crush the cups, and smash the table against his cage. We finally solved the trouble because this baboon fell head over heels in love with one of our testers, a pretty girl named Betty. Tommy was one baboon that Betty literally had eating out of her hand, and when Tommy's memory failed in Betty's presence he blamed himself and not the apparatus. Nevertheless, Tommy's performance dampened our ardour for baboons as standard test monkeys, for we doubted that we would always be assured of an unlimited crop of beauteous and buxom Bettys to serve as testers (see Figs. 3 and 4).

The zoo possessed a number of guenons, slender, graceful, often aesthetically colored, long-tailed Old World monkeys. These animals tested with variable skill; indeed, there appeared to be a distressing positive correlation between their cost and their proficiency.

Although we were not particularly impressed at the time we voted that very satisfactory performances were made by a drab but relatively emotionally stable monkey, the rhesus monkey, one of the sacred monkeys of India. This species subsequently was to become the standard laboratory animal of research in poliomyelitis and for psychobiological research as well.

The performances of the anthropoid apes on the delayed reaction tests were disappointing. One gibbon, the primate that is half-monkey and half-ape, was available to us. This male gibbon, named Charlotte, had a hobby of collecting spectators' spectacles, a hobby abetted by the fact that like all gibbons he was almost all arms and was gifted with unbelievable speed and coordination of movement. His performance on the delayed reaction test, however, was in perfect keeping with the well-known zero correlation between intelligence and simple reaction time.

The performance of the two young chimpanzees was no better than the best of the monkeys. Furthermore, the chimpanzees never seemed to really get down to work and put their hearts into psychological testing. At the time we attributed their good 
Fig. 3 Grooming responses by baboon Tommy to human friend, Betty

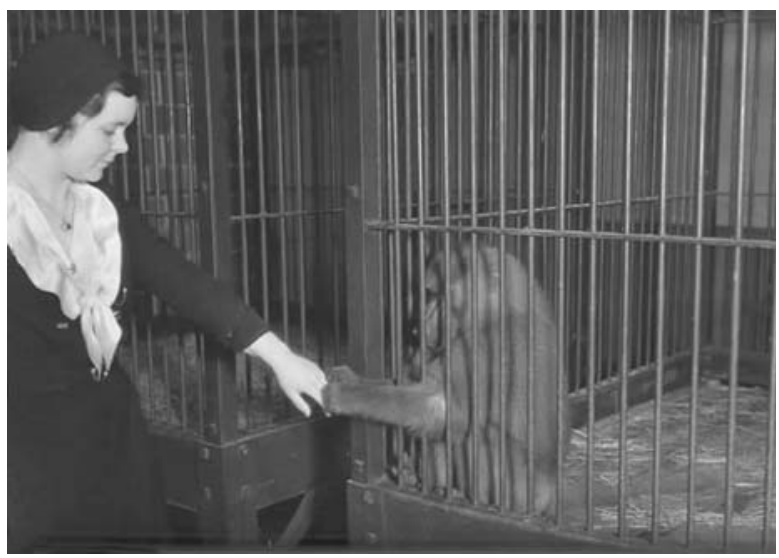

natured distractability to their age, instead of the obvious answer, the fact that they were chimpanzees.

The finest animal in the collection was a 13 -year-old, almost unbelievably tame and gentle orangutan, Jiggs. This anthropoid ape, called by the Sumatra natives "the old man of the woods" looked and played his role to perfection. He was calm and deliberate, and he took his work seriously. Unfortunately he never finished our tests. Less than six weeks after solving and brooding over psychological researches he died of perforated ulcers, and in view of recent advances in psychosomatic medicine we have never been sure that we were without blame.

We worked for almost 2 years at the Vilas Park Zoo, and at the end of that time a building became available on the Wisconsin campus that no one else wanted. This building became our laboratory.

\section{Monkeys in Psychological Research}

When we were first established in the limited facilities that the new laboratory offered we continued our interests in comparative primatology. Rather than standardizing on any particular species we continued to work with many different kinds of simians.

Fig. 4 Aggressive responses by baboon Tommy to Mr. Winkleman who has just threatened and shaken Tommy's friend, Betty

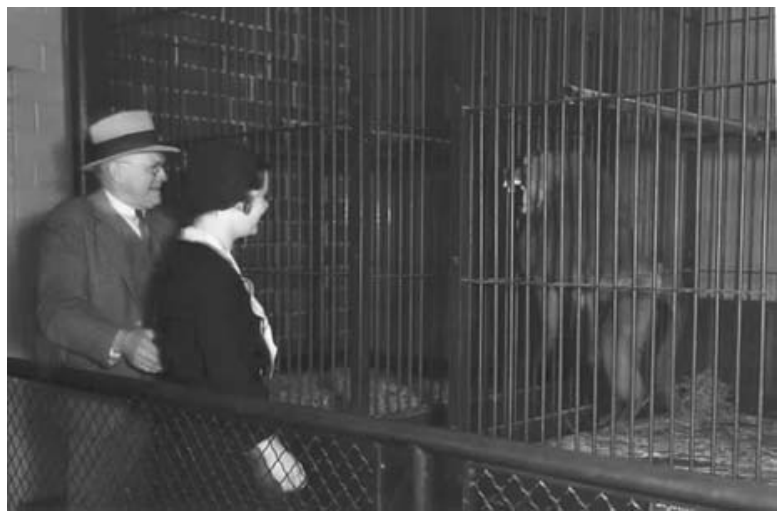


Anthropoid apes were out of the question, but we established a modest monkey colony in which both Old World and New World monkeys were represented.

By some happy chance one of our cebus monkeys turned out to be a fascinating monkey named "Murphy," a monkey endowed - as cebus monkeys sometimes arewith a remarkable, ability to learn instrumentation problems. He was an unusually tame and affectionate little monkey who bit only women and children, and his tool behavior performances have been memorialized in movies and photographs. But we lacked the courage to report his most unusual performance, fearing that our colleagues would believe neither Murphy nor us.

The use by cebus monkeys of sticks as tools has been reported previously by both Romanes (1882) and Klüver $(1933,1937)$ but as far as we knew, no trained observer has ever reported use of tools as a weapon. On June 6, 1935, three students were observing and taking notes on the behavior of four cebus monkeys in a large cage, approximately six feet cubed. One of these animals was our friend, Murphy. The transcribed observations are reported word for word.

"L (Cebus capucinus) had hoarded all the scraps of food left in the cage, sharing with C (Cebus cinnamon) his favorite and lieutenant. M (Murphy) cautiously picked up the crumbs dropped by $\mathrm{C}$. When $\mathrm{C}$ protested, $\mathrm{M}$ picked up a stick and poked at $\mathrm{O}$ (Cebus capucinus) who was sitting near the front of the cage. L attacked Murphy in defense of $\mathrm{O}$ and chased him (M) away. Murphy returned to the front of the cage and shoved a cloth through the bars, flipped it over the food outside, and pulled the food within reaching distance after several such movements. When $\mathrm{L}$ attempted to take the food from Murphy, Murphy picked up the stick from the floor and struck L a hard blow. L fled to the top of the cage screaming. L returned to the attack on $\mathrm{M}$ who again struck at him seven times, missing twice (These blows were directed downward and with considerable force. Murphy seemed to manipulate the stick with fair ease despite the fact that he had never been known to use a stick for striking at any time prior to this). Murphy continued to poke L with the stick after he had sought safety in an upper corner of the cage."

One can, of course, question the validity of the report because it is not substantiated by objective record other than written word. The senior observer, however, was a scientist, an anthropologist, and a Methodist minister, and we have faith in his accuracy and honesty.

Although I personally never saw Murphy strike another animal with a stick, I did observe him use a stick in such a way that it might be considered to be a weapon. Attracted one afternoon by the fear-threatened cries of monkeys, I hurried to the selfsame observation cage and saw Murphy and another cebus in one corner, surrounded by five rhesus monkeys. While I watched, Murphy picked up a stick and flailed at the rhesus monkeys but did not hit, or come particularly close to hitting, any of them. The rhesus monkeys, perhaps awed by this secret and terrifying weapon, gave ground and their threatening behavior ceased shortly afterward.

Perhaps we should be criticized for not reporting these behaviors earlier, but in my defense let me state that in the mid-30s comparative psychology had attained a level of objectivity that made reporting such behavior a matter of grave risk to the reputation of any ambitious young scientist, and it is better to become famous slowly than to be right all at once. 
These observations, or hallucinations as the case may be, led us to systematically investigate his tool using capabilities under more conventional and less bellicose conditions, and the observations and photographic records gave us information which proved useful in later theorizing. Murphy was a very versatile engineering student, but in the long run we believe we learned more from him, than did he from us.

Another New World monkey was an adult spider monkey, Grandma. Spider monkeys have tails that are so prehensile that they truly serve as a fifth hand. Grandma quickly demonstrated to us that some South American monkeys, at least, could solve very long delayed reactions, and she demonstrated it in a most spectacular way. When the cups were placed beyond arm's reach, she backed against the cage, knocked over the correct cup with her tail and carried the piece of banana to her mouth with the same organ. As far as we know, Grandma was the only animal with a tail that could think. But there is an even more remarkable tale about Grandma. High above her indoor living cage and obviously out of arm's reach was an electric light with a pull chain, and Grandma used to wile away the evening hours by grasping the chain with her tail and turning the light on and off. The University night watchman once passed the lab and seeing the light on, went in to turn it off. As he opened the door darkness descended. He turned on his flashlight, but no one was downstairs. He rushed upstairs to catch the intruder, and the light downstairs went on. He rushed downstairs and the light was off - and no one was there. He returned upstairs and the light went on, but it was off when he returned, and the culprit had vanished. Doubting his sanity he left, looked back a last time and saw the light come on. The watchman had had enough, but Grandma continued to be always curious.

The constant, compelling curiosity of the New World monkeys fascinated us, and we started to carry out systematic researches on these behaviors. But before the researchers were well underway the colony was destroyed by a scourge of tuberculosis, and 15 years passed before we again initiated researches in this area. The near total destruction of our colony by the TB plague was not an unameliorated disaster. The unpleasant consequences of the loss of the colony forced us to make decisions that were to prove important. We determined to move our living quarters out of the main building and to concentrate our efforts on a single monkey species.

Actually the epidemic was merely the precipitating condition behind both changes. Housing and testing monkeys in close proximity is an undesirable arrangement. Although monkeys may be trained to ignore most disturbances, they are especially susceptible to the distraction of sounds of other monkeys, the sounds of threatening, fighting, and food calling. The separation of cagemates may lead to distress calls, and cagemates that are in position to call back and forth may prove extremely resistant to taming and testing practices. The extreme illustration of this that we have observed is the disruption of the female's test behavior in response to the barely audible calls of her infant from which she has been separated.

Many factors had also led us to believe that concentration on a single monkey species was desirable. The devotion of psychologists, beyond lip service, to the study of the comparison of the abilities of various animal species had waned by the mid-thirties, and psychologists were then becoming progressively more interested in the use of subhuman subjects in the study of such fundamental problems. There was a constant trend among psychologists toward more formal and rigid experimental designs, and these demands could not be met by using a guenon, a baboon, two 
cebus monkeys, and three macaques as subjects in any experiment. As our testing techniques had become more refined we had ourselves become more interested in studying the detailed, quantitative types of problems that were attracting increasing psychological attention. Finally, small sample statistics were coming into vogue and we realized that the results of monkey experiments could be given adequate statistical expression if we selected and concentrated on a basic test animal.

The problem of living quarters was easily solved because the University generously allowed us to design and build housing facilities at our own expense. These facilities consisted of 16 cages approximately $3 \mathrm{ft}^{2}$ located within a frame building with access through short run-ways to outside wood and wire cages approximately $3 \mathrm{ft}$ wide, $6 \mathrm{ft}$ long, and $6 \mathrm{ft}$ high. Each double cage was large enough to hold a pair of monkeys. The cage facilities are illustrated in Fig. 5. Free access between the inside and outside cages was provided by doors hinged at both ends of the runways, and our rhesus monkeys have always taken full advantage of these privileges winter and summer. Casual visitors in winter have often marveled at the sight of monkeys playing in the snow.

\section{The Rhesus Monkey in Psychological Research}

The construction of living quarters outside the main laboratory building became an important factor in determining our selection of the rhesus monkey as the species which we accepted for standardized psychological testing. We knew that cebus and spider monkeys could not be adequately maintained in the living quarters we had provided. Our limited experience indicated that these New World monkeys were much more susceptible to the effects of temperature changes than the rhesus monkey, and these facts were in keeping with information concerning the feral living conditions of the various species. The South American monkeys are tropical animals, the rhesus

Fig. 5 Monkey inside living cages

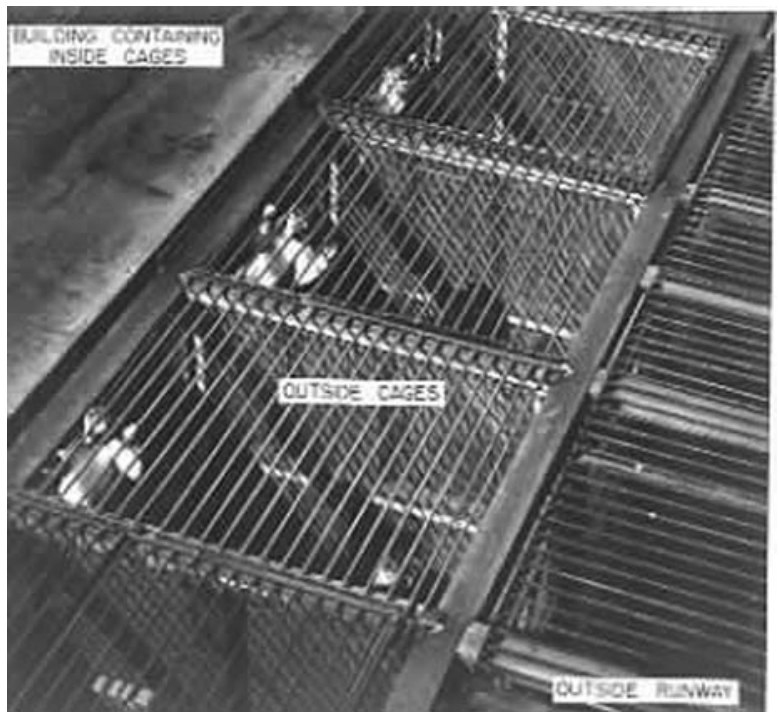


monkeys are not. The latter live under temporate climatic conditions in geographical areas in which snow may fall in winter. The rhesus monkey exposed to cold grows a thick fur coat which he puts in storage in the spring.

We knew that rhesus monkeys would do well in our new quarters (which had heat inside) for the winter before the TB epidemic struck we had housed five rhesus monkeys in an unheated, straw filled shed outside the laboratory, and these animals survived the winter and the disease. Indeed, we had never seen such healthy rhesus monkeys as were these at the winter's end-exactly as Mr. Winkleman, Director of the Madison Zoo, had predicted.

Resistance to temperature change does not appear to be the only factor making the rhesus a hardier laboratory animal than the South American monkeys. Far more South American monkeys fail to adapt to laboratory conditions within the first month of arrival, either as a result of disease or dietary difficulties. The South American monkeys are highly insectivorous, and it is possible that the diet provided by laboratories is either inadequate, or is a diet to which these animals have difficulty in making an initial adjustment. But temperature and known dietary problems aside, the cebus or spider's average life span under zoological or laboratory conditions is considerably shorter than that of the rhesus monkey, and predicted life span is an important factor influencing the planning and design of many psychological researches.

Our most fundamental reason for selection of the rhesus monkey as a standard test primate lay in the fact that we had gradually come to appreciate their behavioral capabilities in informal test situations. Although these monkeys are almost devoid of personality, in the common sense meaning of the term, they are stable and dependable test subjects, that tame rather readily and adapt to experimental test conditions in a highly satisfactory manner. The rhesus monkey lacks the gay abandon of the cebus monkey, the elegant grace and composure of the spider, or the buffoonery of the chimpanzee. But beneath the gray or grim exterior of the rhesus is a central nervous system waiting to grind out a hundred test trials a day. The difference between a cebus monkey and a rhesus is all the difference between a southern belle and a New England store keeper. Our primary interests concerned learning and intelligence.

The final reason for choosing the rhesus monkey was that this animal had already become the standard monkey for neurological, physiological, biochemical, and pharmacological research. We had long been interested in neurophysiology and wished to take all possible advantage of basic information obtained in this field. We believed that more information on diet and disease in the rhesus monkey would accrue than for any other subanthropoid, and this faith was to prove more than justified. We selected the rhesus monkey as the standard primate for behavior testing because we believed that we would have the greatest opportunity to profit from the work of others, and that conversely our behavioral data would prove most valuable to those in other disciplines who wished to correlate the data of their disciplines with those data of behavior science.

Our choice of the rhesus monkey proved very fortunate because this animal was becoming the standard primate to be used in many laboratories and in many scientific disciplines. Additional information was rapidly being made available concerning adequate housing, maintenance, and medical care. Control over the worst 
scourge, tuberculosis, was greatly facilitated by the tuberculin test which made it possible to identify infected animals, and this test combined with isolation of incoming monkeys makes control of the white plague practical. Furthermore, the sulphonamides and subsequently the antibiotics were to prove as effective medical agents for monkeys as for men.

The advent of effective diagnostic tests and therapeutic drugs has been extremely important in determining the design of experiments and the choice of experiments amenable to test by primates. Long term psychological researches on monkeys in the mid-thirties were extremely risky because of the constant threat of epidemic diseases which could destroy or decimate normal and control groups, and summarily terminate an experiment or destroy any semblance of an experimental design. Without question the constant threat of tuberculosis, pneumonia, or dysentery operated as a strong deterrent to the acceptance of the monkey as a standard laboratory animal for psychological researches, or at the very least the threat of these diseases suggested to the bravest primatologist the wisdom of short-term rather than long-term researches. Fortunately, cause for this fear has now been largely dispelled, and researches requiring months or years may be attacked using rhesus monkeys with assurance that only a small per cent of the work will be invalidated by loss or serious illness of subjects.

\section{Progress and Problems in Long-Term Primate Research}

Control of disease and consequent laboratory longevity on the part of our monkey subjects did far more than change the precision of our experimental designs or the mean length of our planned problems. The very facts of longevity altered out attributes both toward monkeys and psychological experiments. As our monkeys were tested year after year on progressively more complex problems, we were forced to accord to these animals a level of ability in problem solution that had never previously been demonstrated. Furthermore, after we demonstrated the remarkable ability of monkeys to solve problems, the selfsame abilities were demonstrated for the chimpanzee. Thus it was that the antibiotics and consequent intellectual maturity raised both the monkeys and the apes to a phyletic level to which they had not previously aspired after $100,000,000$ years of primate evolution. As the abilities of the monkeys became more and more evident, it was inevitable that formal experiments to determine the long-term course of the learning process should be designed, and these investigations led to the discovery of heretofore unexploited areas of psychological research. It is not our wish to discuss these researches in detail here; we desire only to emphasize that the contributions made indirectly by scientists outside the field of psychology have been of the greatest importance to our researches, and that these contributions will prove even more important to the primate researches of the future, as research interest shifts progressively to long-term and genetic studies.

Our somewhat unwitting and accidental involvement in monkey gerontology has not been an unmixed blessing and has been attended by many problems, some of which still remain to be solved. The immature and mature rhesus monkeys have, just like human beings, different personality structures. Ten-year-old macaques weighing $20 \mathrm{lb}$ or more cannot be cajoled or coerced to enter transport cages as simply as 
infant animals, even though this has seldom presented a problem, and never a problem that could not be solved by individual housing and suggestive therapy such as the threat of a very mild electric probe or air blast. Fully mature animals, particularly males, that have been docile and faultless test machines for almost a decade, may become unreliable subjects that cannot be depended upon to complete a full test day week-in and week-out. The best prophylaxis against this disorder is continuous testing by able and experienced testers. We have tried other procedures with some success, such as castration of adult males, but we regard this as a sacrifice almost beyond the call of duty.

The most surprising, and for a time difficult, interpersonal relations problems that we encountered were not those between men and monkeys themselves. If pairs of rhesus monkeys are housed in adjacent cages they develop a "cage consciousness" with a within cage in-group and between cages outgroups. The young animals engage in cage fights no more or less rational than Balkan wars, characterized by raucous outcries and attempts to snatch each others' limbs or fur. The aroused monkey apparently cannot inhibit snatching, even though his hand may be seized and effectively immobilized by the monkey in the neighboring cage. This activity has no serious consequences among young animals, but as our monkeys became mature we were horrified at the consequences. The helpless aggressor would end with a hand lacerated, and frequently a finger completely severed. Guided by both humanitarian and practical motives - a colony of educated but fingerless monkeys would have been of little use to us - we rapidly reconstructed our cages so that no animal could reach into another's cage. This appears to be an absolute necessity with mature rhesus monkeys.

\section{Primate and Subprimate Subjects}

As we have already indicated, we chose the rhesus monkey as our standard test animal because we believed he was the most generally efficient psychological subject within or without the primate order. The specific characteristics that make this animal or any other animal a good psychological subject are detailed as follows. Most young rhesus monkeys are good psychological subjects because they readily adapt to taming. Within a few weeks they may be used as test animals, and in only a few months they usually become stable and dependable subjects. The well-adapted rhesus may be used in an experimental design requiring completion of 50 to 100 trials a day, and exceptional animals can be tested on much longer sequences. A thoroughly tamed rhesus will accept a considerable amount of distraction without serious decrement in performance, and he will accept frequent errors and frustrations without abandoning the problem. Twenty years ago I had the opportunity to test a group of seriously defective, institutionalized children, and the many similarities between these children and thoroughly institutionalized rhesus monkeys has always remained vivid. Seldom have so many subjects, done so much work, for so little rewards, and still turned out performances that must have been so near their theoretical limits of performance. A rhesus monkey can become a finer robot than any electrical engineer will ever devise-willing, ready, and moderately-able. Furthermore, the rhesus monkey can think, and despite the IBM slogan this remains a goal, not an achievement, for their machines. 
The anthropoid apes are doubtless more intelligent animals than the rhesus monkeys, but they seldom become such ideally, automatic, unquestioning, problem solving machines as the monkeys. Just as the defective child is a more stable, dependable, and tractable test animal than the normal child, so is the relative uncurious and undistractable rhesus a more stable test machine than the chimpanzee. We would not for a moment recommend that psychologists cease either to rear or test normal children or chimpanzees and concentrate on defective children and monkeys. Psychology is a broad field, there is work for all, and it is a matter of every man to his own taste.

The usefulness of the monkey as a psychological subject is vastly enhanced by the wide range of problems on which he may be tested. His sensory capacities are so closely akin to man that reception is seldom, if ever, a problem in terms of experiments designed by human beings. He has demonstrated to be an effective performer on problems ranging from simple conditioning to complex multiple sign problems as involved, if not more involved than those solved by any subhuman form. Within a single class of problems, such as discrimination problems, test conditions may be arranged so that extremely rapid or extremely slow learning may be produced and analyzed, depending on the interests and whims of the experimenter at any particular time. The motivational mechanisms for the monkey are diverse and humanoid enough to provide a relatively inexhaustible source for future researches. The potentialities of the rhesus monkey as a subject for social investigations, both normal and abnormal, have never been thoroughly and intensively analyzed, but the kinship of man and monkeys suggests that the rhesus should prove a subject of vast value in this relatively uncharted area.

Our enthusiasm for the rhesus monkey is not based on prejudice, and we are not blind to the usefulness of other animals. There is every reason to believe that the squirrel monkey and the marmoset would make efficient and useful psychological subjects if stable colonies - preferably breeding colonies - could be established. Enough psychological research has been done to demonstrate that both of these species are capable test primates, and they possess certain advantages over the macaque. They are apparently more primitive primates, and their relatively unfissurated brains offer opportunities for psychoneurological investigations that are technically unsolvable using the higher primates with their more complexly fissurated cortices. Furthermore, both the squirrel monkeys and the marmosets are very small animals that mature rapidly. If stable colonies could be established, they would be cheap to maintain, easy to house, and would offer the possibility of conducting primate inheritance studies within reasonable periods of time and at reasonable expense.

Perhaps the greatest bars to routine use of the rhesus monkey as a psychological test subject lie in his relatively large size and his relatively high cost. Actually the rhesus monkey is smaller than most dogs, and for a large part of his test life is little larger than a cat, and the monkey adapts as well or better to laboratory living and is no more subject to serious disease, and is far more versatile in his range of behavioral capacities. The monkey is more troublesome and more expensive than either rats or pigeons, and this is fortunate in that otherwise no adequate psychological rodentology or avianology would ever develop. The advantages of the monkey over these subprimate forms, with their relatively limited behavioral 
range capacities, are self evident, just as the advantages of the rat and the bird over the monkey and the chimpanzee for certain kinds of psychological research are equally self evident. To ever espouse the case for one animal as opposed to another would, of course, be sheer nonsense. Psychologists are fortunate to have available a wide variety of animal forms, many of which have special traits and characteristics that ideally fit them for particular types of psychological research. The psychologist's problem is merely to find the particular species best adapted for the particular problem and to recognize that no one animal is better than any other-with the exception of the rhesus monkey.

Open Access This article is distributed under the terms of the Creative Commons Attribution Noncommercial License which permits any noncommercial use, distribution, and reproduction in any medium, provided the original author(s) and source are credited.

\section{References}

Klüver, H. (1933). Behavior mechanisms in monkeys. Chicago: University of Chicago Press.

Klüver, H. (1937). Re-examination of implement-using behavior in a cebus monkey after an interval of three years. Acta Physiologica, 2, 347-397.

Romanes, G. J. (1882). Animal intelligence (2nd ed.). London: Kegan Paul, Trench.

Harry F. Harlow (1905-1981) was Professor of Psychology at the Universtiy of Wisconsin-Madison from 1930 until his retirement in 1974. In his early work, Harlow focused on learning capabilities of different primate species, but he became world-famous with his work on maternal separation and social isolation experiments with rhesus monkeys. 